Revista Perspectivas Online: Humanas \& Sociais Aplicadas Dezembro de 2018, Vol.8, n 23, p.71-75

ISSN: 2236-8876(Online)

DOI: $10.25242 / 887682320181680$

\title{
A ARQUITETURA E O DESIGN DA SALA DE AULA NO SÉCULO XXI: A NECESSIDADE DA CRIATIVIDADE NA ESCOLA
}

\author{
Alber Neto $^{1,2 *}$ \& Amanda Barcellos da Silva ${ }^{1}$ \& Julia Vizella Baltazar Paes ${ }^{1}$ \\ \& Marcos Italo Barcelos Fagundes ${ }^{1}$ \& Matheus Vasconcelos Quadros ${ }^{1}$ \& Milena Manhães Miranda ${ }^{1}$
}

\begin{abstract}
RESUMO
NETO, A.; SILVA, A.B.; PAES; J.V.B.; FAGUNDES, M.I.B; QUADROS, M.V.; MIRANDA, M.M. A arquitetura e o design da sala de aula no século XXI: a necessidade da criatividade na escola. Perspectivas Online: Humanas \& Sociais Aplicadas Perspectivas Online: Humanas e Sociais Aplicadas, v. 8, n.23, p. 71-75,2018.
\end{abstract}

Por meio de pesquisa bibliográfica, o artigo apresenta a problemática do projeto de pesquisa "A arquitetura e o design da sala de aula no século XXI: requisitos para uma sala makerspace". Assim, é abordada a denominada Quarta Revolução Industrial, as implicações desta no futuro do trabalho, a necessidade de modernização da educação formal, o makerspace como nova concepção de sala de aula e um entendimento sobre a relevância da criatividade em todo este contexto delimitado.

Palavras-chave: sala de aula; makerspace; criatividade.

\section{ABSTRACT}

Through a bibliographical research, the article presents the problematic of the research project "The architecture and the design of the classroom in the 21st century: requirements for a makerspace". Therefore, address the Fourth Industrial Revolution, the implications of this in the future of work, the need of a formal education modernization, the makerspace as a new conception of classroom and an understanding of creativity relevance in this delimited context.

Keywords: classroom; makerspace; creativity.

\footnotetext{
${ }^{1}$ Institutos Superiores de Ensino do CENSA - ISECENSA - Rua Salvador Correa, 139, Centro, Campos dos Goytacazes, RJ, CEP: 28035-310, Brasil;

${ }^{2}$ Universidade de Lisboa - ULISBOA - Faculdade de Arquitetura - Rua Sá Nogueira, 1349-063, Lisboa, Portugal.

(*) e-mail: alberneto@gmail.com

Data de recebimento: 23/07/2018. Aceito para publicação: 21/12/2018
} 


\section{INTRODUÇÃO}

Dentro de pouco tempo, para ter um emprego, o indivíduo necessitará ser o máximo diferente possível de um robô: criativo, ter pensamento crítico e habilidoso socialmente. Por isso a mudança no sistema educacional é urgente. As instituições de ensino atuais, em sua grande maioria, continuam seguindo o padrão daquelas que foram pensadas para preparar o indivíduo que trabalharia nas fabricas do século XIX. Na Revolução Industrial, o indivíduo iria integrar uma força de trabalho que estariam em silêncio o dia todo, isolados uns dos outros, seguindo um comportamento padrão, a fim cooperar com uma produção em massa nada versátil. Criatividade, pensamento crítico e colaboração eram características que o setor produtivo desencorajava (BROWN-MARTIN, 2015).

Esta urgência remete ao início da Quarta Revolução Industrial que vive-se hoje. Genética, inteligência artificial, robótica, nanotecnologia, impressão 3D e biotecnologia - entre tantos outros, são campos que estão se desenvolvendo e fortalecendo uns aos outros. Esses campos emergentes serão a fundação para uma Revolução mais intensa e abrangente. Sistemas inteligentes (em casas, fábricas, fazendas, comunidades e cidades) ajudarão a contornar problemas de todos os tipos, da cadeia de suprimentos às mudanças do clima, tudo será mais dinâmico. A consolidação da cultura do faça você mesmo (ou do it yourself - DIY) e da economia compartilhada permitirá pessoas a rentabilizarem suas próprias casas e carros (SCHWAB \& SAMANS, 2016).

Mas quando a escola continua a repreender a criatividade ao longo do desenvolvimento do ser, o aluno torna-se resistente a esta habilidade durante o ensino superior e tende a chegar cada vez mais defasado no mercado de trabalho. Pensa-se que a escola deveria se preocupar não somente com a leitura, escrita e aritmética; deveria também incentivar a criatividade, inovação e empreendedorismo (ROBISON, 2011).

Geralmente, as crianças não crescem em um contexto familiar criativo. E frequentemente recebem uma educação formal também não criativa. Criatividade é um processo multifacetado. $\mathrm{E}$ envolve muitas habilidades comuns, algumas habilidades rebuscadas e técnicas; pode ser estimulada por diferentes visões de mundo, e sustenta-se no pensamento crítico e também na imaginação. As formas de educação dominantes reprimem ativamente as condições essenciais ao desenvolvimento criativo. Crianças entram na pré-escola com uma vigorosa confiança criativa; com o tempo, muitos deixam o ensino médio enquanto jovens que perderam a criatividade. É importante intender o porquê e como isto acontece. Existem maneiras pelas quais adultos podem reascender a criatividade em si mesmos e nos outros. Mas ao passo que a criatividade torna-se um tema central em nossos futuros, tem de se tornar tema central da educação (ROBISON, 2011).

Ainda restrito a escolas particulares de ponta, cita-se o denominado makerspace como um novo entendimento de sala de aula pensado para que a criatividade seja exercitada. Certamente, a criatividade deve ser uma questão de nível estratégico em uma instituição de ensino, envolve questões pedagógicas. O makerspace não exaure a discussão, mas — junto de uma propostas pedagógica pode potencializar a criatividade no contexto escolar.

Como não existe uma definição padrão, neste momento, pode-se dizer que makerspace (libary makerspace) é o nome dado aos espaços de uso coletivo e colaborativo equipados com máquinas, ferramentas e materiais que possibilitam o desenvolvimento e a prototipação de produtos físicos e digitais. Estão fortemente atrelados a cultura do faça você mesmo. E ainda: 
- Fablab, por sua vez, é o nome dado aos espaços de uso coletivo e colaborativo equipados com máquinas e ferramentas que possibilitam o desenvolvimento de produtos digitais.

- Hackerspace se assemelha ao supracitados, mas se vale também dos princípios da cultura hacker -- fortemente atrelado ao libertarianismo e coletivismo. Pode-se dizer que está mais focado em transformar coisas para que funcionem de uma maneira diferente do que fora projetado incialmente.

Em um cenário atual onde identifica-se a necessidade de trabalhar a criatividade no contexto da educação escolar, e onde apenas $11,5 \%$ das 131.606 escolas de ensino fundamental brasileiras possuem laboratório (INEP, 2018), o objetivo da pesquisa relata aqui é compreender como um makerspace pode ser implementado, buscando dar ênfase as soluções de baixo custo. E ainda: identificar os requisitos arquitetônicos para um makerspace; identificar e catalogar objetos e equipamentos que podem compor uma sala makerspace; formalizar recomendações que venham a auxiliar projetos de salas de aula makerspace de baixo orçamento. Neste artigo, especificamente, o objetivo é apresentar uma compreensão sobre a criatividade e a sua relevância para o futuro do trabalho na Quarta Revolução Industrial.

\section{METODOLOGIA}

Em um primeiro momento, descreve-se que quanto a abordagem do problema delimitado, tem-se um pesquisa qualitativa. E quanto aos objetivos listados, uma vez que busca-se criar certo entendimento sobre uma determinado tipo de ambiente projetado (sala de aula) por meio da análise de experiências diversas, pode-se dizer que se trata de uma pesquisa exploratória.

Assim, os dados para consolidação da pesquisa serão formalizados a partir de documentação indireta (pesquisa bibliográfica) e por meio de documentação direta - quando de visitas técnicas em escolas na cidade de Campos dos Goytacazes (RJ) e Lisboa (Portugal).

\section{FUNDAMENTAÇÃO TEÓRICA}

No âmbito da pesquisa aqui relatada, criatividade é abordada enquanto a característica humana que envolve o ato de pensar em alguma coisa nova e criar esta alguma coisa nova.

A criatividade, portanto, não está condicionada a criação de alta tecnologia ou modelos de negócio disruptivos. É uma característica que pode ser praticada no dia a dia, envolve pensamento crítico e comportamentos que devem ser cultivados - deve ser um hábito. Logo, a criatividade não deve estar restrita apenas a profissionais como designers e arquitetos, por exemplo. O ambiente favorece o desenvolvimento da criatividade, por isto a escola deve ser protagonista. A criatividade é um ativo social, não apenas individual (FLORIDA, 2014).

A partir de Ken Robinson (2008) e Richard Florida (2014) é possível discorrer que a palavra criatividade não deve ser atrelada como sinônimo da palavra inteligência. Criatividade é uma habilidade cognitiva dentre outras funções mentais, e o conjunto complexo de habilidades cognitivas e 
funções mentais é aquilo que se denomina inteligência. A inteligência se refere ao poder de entender, processar e lidar com grandes quantidades de dados, e a criatividade só tem a favorecê-la.

Pensa-se que habilidades criativas devam ser desenvolvidas nos indivíduos para que os mesmos possam se integrar a denominada Quarta Revolução Industrial — onde se caracteriza uma dinâmica de rápido desenvolvimento e um processo de inovação contínuo.

Fazer com que a criatividade seja um tema da educação formal é uma demanda real. Pois enquanto jovens tem dificuldades de se empregarem, os empregadores se queixam da escassez de jovens que tenham as habilidades necessárias para as vagas disponíveis. E esta incompatibilidade tende a se agravar: entre os primeiros empregos que os jovens conseguem atualmente, $70 \%$ será demasiadamente diferente ou deixara de existir nos próximos 10 a 15 anos (devido a sistemas de inteligência artificial e automação); $50 \%$ dos empregos irão necessitar de habilidades que estão sendo suprimidas pelas instituições de ensino (FYA, 2015).

Susskind, \& Susskind (2017) discorrem a partir do determinado exemplo: sempre foi necessário um conjunto distinto de habilidades operacionais para se fazer um tradicional espresso. Mas nas últimas décadas, o surgimento e popularização de produtos como Nespresso e Lavassa fez com que o preparo de um espresso fosse reduzido a introdução de um capsula em um máquina. A ação humana está em colocar a capsula na máquina e apertar um botão. Certamente, não significa a morte de toda uma cultura ao redor do espresso, mas sugere uma reflexão sobre a necessidade de habilidades estratégicas e criativas frente a habilidades operacionais. E este tipo de reflexão cabem a todas classes profissionais.

O rápido desenvolvimento tecnológico não pode ser visto como uma competição entre o homem e a máquina, mas sim como uma oportunidade para indivíduos lidarem com ferramentas que irão possibilitar um melhor desempenho profissional. O setor produtivo (empresas e industrias), o governo e os indivíduos precisam repensar a educação a fim de que uma força de trabalho criativa, inovadora e empreendedora venha a se estabelecer (WEF, 2016).

\section{CONSIDERAÇÕES FINAIS}

O século XXI apresenta desafios e questionamentos sobre o futuro do trabalho, e pensa-se que habilidades criativas podem vir a auxiliar os indivíduos se adaptarem ao cenário de inovação contínua. E arquitetos e designers, como profissionais preponderantes no processo de produção e consumo, têm a missão de entender novos fenômenos afim de que seus projetos extrapolem a fruição estética e auxiliem o desenvolvimento humano e social.

Como fora versado, considerando a dinâmica da Quarta Revolução Industrial e o futuro do trabalho, a criatividade passa a ser assunto relevante e necessário no contexto da educação formal. Reforça-se o ambientes do tipo makerspace não exaure a discussão, mas pensa-se que pode potencializar a criatividade nas instituições de ensino. E apresentar requisitos projeturas para makerspaces é uma das formas que arquitetos e designers podem contribuir para fomentar a criatividade no contexto da educação formal. 


\section{REFERÊNCIAS}

BROWN-MARTIN, G. Learning $\{\mathbf{R e}\}$ imagined: how the connected society is transforming learning. Bloomsbury Academic, 2015.

INEP. Censo Escolar 2017: Notas Estatísticas. 2018.

FLORIDA, R. The Rise of the Creative Class, Revisited. Basic Books, 2014.

FYA. The New Work Order: ensuring young Australians have skills and experience for the jobs of the future, not the past. 2015

ROBINSON, K. Out of Our Minds: Learning to be Creative. 2.ed. Capstone, 2011.

SCHWAB, K.; SAMANS, R. The Future of Jobs: Employment, Skills and Workforce Strategy for the Fourth Industrial Revolution. World Economic Forum, 2016.

SUSSKIND, R.; SUSSKIND, D. The Future of the Professions: How Technology Will Transform the Work of Human Experts. Oxford University Press, 2017.

WEF. The Future of Jobs: Employment, Skills and Workforce Strategy for the Fourth Industrial Revolution. World Economic Forum, 2016. 